\title{
Incorporation of Nuclear Wastes in Lead-Iron-Phospate and Uranium containing LIP Glasses
}

\author{
A. GHOSH ${ }^{1}$, G. HAZRA ${ }^{2}$, P. MITRA ${ }^{3}$ and T. DAS ${ }^{1 *}$ \\ ${ }^{1}$ Department of Chemistry, The University of Burdwan, Burdwan - 713 104, India. \\ ${ }^{2}$ Department of Chemistry, Kalna College, The University of Burdwan, Burdwan - 713 409, India. \\ ${ }^{3}$ Department of Physics, The University of Burdwan, Burdwan - 713 104, India. \\ ${ }^{*}$ Corresponding author E-mail: tdas.bu@gmail.com \\ http://dx.doi.org/10.13005/ojc/300111
}

(Received: December 12, 2013; Accepted: January 19, 2014)

\begin{abstract}
Glasses in lead-iron phosphate (LIP) system loaded with simulated nuclear waste, were melted in the temperature range $750-950^{\circ} \mathrm{C}$. Some of the LIP glasses were mixed with uranium salt. The $\mathrm{pH}$ determinations of the leachate solution at normal temperature show some interesting trends. Leaching study of these glasses with a maximum time period of $300 \mathrm{hrs}$. were conducted under Soxhlet distillation condition with distilled water. Weight losses and residual activities by 'Radiotracer technique' were followed with respect to cumulative time period of leaching. For some LIP-glass samples containing uranium the leach rates as calculated from BET surface area measurements. They were in the range $8.2 \times 10^{-4}$ to $1.8 \times 10^{-3} \mathrm{~g} \cdot \mathrm{m}^{-2} \cdot \mathrm{hr}^{-1}$ at $90^{\circ} \mathrm{C}$. DTA endotherms occur at $\sim 400^{\circ} \mathrm{C}$ and $\sim 900^{\circ} \mathrm{C}$ for the LIP glasses. FTIR studies show absorptions at $\sim 532, \sim 1025, \sim 1620-1640$, $\sim 2365$ and $\sim 3440-3490 \mathrm{~cm}^{-1}$. SEM of some selected glasses was reported. The variation of different properties was explained in terms of the changes in the ionic potentials of the different modifier ions. The model structure of glasses has been considered taking the dual role of $\mathrm{Fe}^{3+/ 2+}$ and $\mathrm{Pb}^{2+}$ as glass formers/ modifiers which ultimately has an effect on the chemical durability of these glasses.
\end{abstract}

Key words: Nuclear Wastes, Uranium, LIP Glasses.

\section{INTRODUCTION}

The future development of nuclear energy depends largely on the success of programmes and management of radioactive wastes generated at various stages of the nuclear fuel cycle. A nuclear (radioactive) waste is any material that contains or is contaminated with radionuclides at concentrations greater than a certain safe (permissible) level. Radioactive wastes are generated from the various sources such as nuclear power plants, medical isotope applications, defence, communication systems and atomic industries. The fission products with the usual fuel materials viz., $\mathrm{U}, \mathrm{Pu}$, and Th contain about 35 elements with 200 different isotopes. Besides the fission products, the waste contains unrecovered $\mathrm{U}, \mathrm{Pu}$, corrosion products like $\mathrm{Fe}, \mathrm{Co}, \mathrm{Ni}, \mathrm{Al}, \mathrm{Na}$ and the anions $\mathrm{NO}_{3}{ }^{-}$and $\mathrm{SO}_{4}{ }_{4}^{2-}$. The corrosion products come from the stainless steel process vessels, which are attacked by acid solution ${ }^{1}$. 
Glass offers a medium for waste containment since it has the ability to dissolve most of the elements of the periodic table. The fission product constituents thus become a part and parcel of the glass structure as compared to any other mechanical entrapment. Glass can be considered as a truly 'secular' matrix, imbibing in one melt all the elements contained in the waste. This results in a permanent and irreversible fixation of the nuclides in the various matrix. Glass has very high leach resistance, i.e., it does not dissolve easily in water. High leach resistance is one of the most desirable properties of the solid matrix used to immobilize the fission product. It is the leach resistance value which dictates the selection of glass as a nuclear waste glass ${ }^{2}$. Since these glasses are to be stored for several thousand years under such conditions before the radioactivity dies down, corrosion study of such glasses under varying environmental conditions is helpful in understanding the durability and fission product release from such glasses.

Since millions of curies of activities will be stored in such glasses emanating huge amount of radiation, it will be useful to see the effect of radiation on leachability. Lead iron phosphate glasses have several advantages such as lower aqueous corrosion rate, lower processing temperature, etc ${ }^{3-5}$. In addition, these glasses did not vitrify upto $550^{\circ} \mathrm{C}$. Lead iron phosphate glasses (LIP) are a potential candidate for immobilization of high level commercial and defence radioactive waste with leach rate $10^{2}-10^{3}$ times lower than the leach rate of a comparable borosilicate waste glass ${ }^{6}$. The composition of the nuclear wastes used in the present work is shown in Table 1.

\section{EXPERIMENTAL}

\section{Preparation of glass batches and melting operation}

The glass batches used in the present work were prepared from the ingredients like quartz powder (AR grade, Oxford laboratory reagent) as source of silica, Borax (AR grade, RANKEM), $\mathrm{PbO}$ (AR grade, Dipak laboratories), BaO (AR grade, Boroyne), $\mathrm{CeO}_{2}$ (AR grade, $\mathrm{Hi}$ Media), $\mathrm{SrO}_{2}$ (AR grade, Aldrich), uranyl acetate (AR grade, $\mathrm{BDH}$ ) and $\mathrm{Fe}_{2} \mathrm{O}_{3}$ (AR grade, Dipak laboratories). As source of lead, two ingredients were tried, viz., $\mathrm{PbO}$ and $\mathrm{Pb}_{3} \mathrm{O}_{4}$. The ingredients were dried and taken in a alumina crucibles and fired in a muffle furnace fitted with programmer in the range $750-1000^{\circ} \mathrm{C}$ for soaking periods of $30 \mathrm{~min}-60 \mathrm{~min}$ in air. The oxides $\mathrm{SiO}_{2}$, $\mathrm{B}_{2} \mathrm{O}_{3}$ and $\mathrm{P}_{2} \mathrm{O}_{5}$ act as the glass former while $\mathrm{PbO}$ act as intermediates and $\mathrm{BaO}, \mathrm{SrO}_{2}, \mathrm{CeO}_{2}$ and $\mathrm{Fe}_{2} \mathrm{O}_{3}$ act as modifiers. The compositions used in the present work are shown in Table 2. The selection was based on that supplied by Nuclear Recycle Group (BARC) and also from some predetermined compositions ${ }^{5}$ after reviewing of earlier works in reference to the corresponding ternary diagrams. Some of the LIP glasses [LIP 8 - LIP 10] were composed by taking uranyl acetate directly into itself since $U$ is $\alpha / \beta$ active and by measuring the net counts per sec (cps), the leaching characteristics can be traced by 'radiotracer technique' with the help of a Geiger-Muller counter.

For the $\mathrm{pH}$ determination of the leachate solution, the bulk glass was powdered to $0.3-0.425$ $\mathrm{mm}$ size. One (1) gm of the glass powder was taken in a beaker with $40 \mathrm{ml}$ distilled water. And it was stirred with a magnetic stirrer for 2 minutes. The $\mathrm{pH}$ of the liquid was determined by a $\mathrm{pH}$ meter (Systronics digital $\mathrm{pH}$ meter, Model 335). Such measurements of $\mathrm{pH}$ were carried out at regular intervals of $1 \mathrm{hr}$., 2 hr., $3 \mathrm{hr}$., $4 \mathrm{hr}$. and $5 \mathrm{hr}$. respectively. The mixture was stirred after each 15 minutes. For U-containing LIP glasses, the leachate extract after each operation of leaching for varying time intervals was subjected to $\mathrm{pH}$ measurement.

For leaching studies, the glass samples were crushed to $300-425$ mesh taken in a nylon net. Then $0.5 \mathrm{gm}$ of each sample glass was vapor distilled in Soxhlet apparatus with a round bottom flask (500 ml. capacity) fitted with a condenser ${ }^{8}$. The distillation was carried out for varying period of time up to a maximum of $300 \mathrm{hr}$. The heating was done in a heating mantle. The arrangement is shown in figure 1. The weight loss after each run of leaching was measured by a four-decimal electronic balance (Satorius) and was converted into \% wt. loss. In order to find the leach rates, BET surface area of the U-containing LIP glasses were determined under liquid nitrogen temperature ${ }^{9}$. For LIP glasses, the leaching study was augmented by noting the cps after each interval of time from its residual activity of $\alpha$ and/or $\beta$ with the help of a G-M counter (Nucleonix, Hyderabad, India). 
To obtain information about the thermal characteristics of LIP glasses, Differential thermal analyzer [Perkin-Elmer Diamond TG/DT analyzer] was employed in the range $30-900^{\circ} \mathrm{C}$ under $\mathrm{N}_{2}$ atmosphere, with a rate of $5^{\circ} \mathrm{C} / \mathrm{min}$ using $\alpha-\mathrm{Al}_{2} \mathrm{O}_{3}$ as reference. Higher temperatures were deliberately omitted since melting point of such glasses is close to it. FTIR spectrum of the glasses LIP 8 - LIP 10 was recorded by a spectrometer [Perkin-Elmer FTIR model $\mathrm{RXL}$ spectrometer] using $\mathrm{KBr}$ pellet. SEM image of some glasses were recorded in a Scanning electron microscope [S-530, Hitachi, Japan].

\section{RESULTS AND DISCUSSION}

Table 3 shows the melting temperature and time of melting of different glass compositions obtained in the present work. X-ray diffraction study showed that the products to be amorphous. In melting operation, the temperature and time of meting are the principal factors to be monitored. In the present work we could melt the glass at much lower temperature $\left(750-950^{\circ} \mathrm{C}\right)$ with a soaking period of $30 \mathrm{~min}-1 \mathrm{hr}$ which were earlier reported to be melted not below $1000^{\circ} \mathrm{C}$. The melting temperature of the glass LIP4 was found to be appreciably lower $\left(750^{\circ} \mathrm{C}\right)$ in comparison to other glasse ${ }^{11-12}$. It may be mentioned that in case of LIP4, the modifier oxide is $\mathrm{PbO}$ while for others it is $\mathrm{Pb}_{3} \mathrm{O}_{4}{ }^{13}$. The variation in melting points is due to mixed effect of different modifier ions, the exact trend being difficult to speculate. Considering that the glass will be utilized to incorporate nuclear waste with some of the fission fragment like $\mathrm{RuO}$ which is highly volatile, the lower the glass processing temperature the better will be the utility of the glass melt. The effect of different modifier ions like $\mathrm{Ba}^{2+}, \mathrm{Pb}^{2+}, \mathrm{Fe}^{3+}$ and $\mathrm{Sr}^{4+}$ on the melting points and time of melting is quite evident.

The results of $\mathrm{pH}$ studies are shown in

Table 1: Compositional details of simulated low and intermediate level radioactive liquid waste

\begin{tabular}{llcc}
\hline $\begin{array}{l}\text { S. } \\
\text { No. }\end{array}$ & Properties & $\begin{array}{c}\text { Low level radioactive } \\
\text { liquid waste }\end{array}$ & $\begin{array}{c}\text { Intermediate level } \\
\text { radioactive liquid waste }\end{array}$ \\
\hline 1 & $\mathrm{PH}$ & $8-9$ & $9-13$ \\
2 & $\mathrm{CsNO}_{3}$ (milimoles/L) & $6.56 \times 10^{-6}$ & $8.39 \times 10^{-4}$ \\
3 & $\mathrm{Sr}^{2}\left(\mathrm{NO}_{3}\right)_{2}$ (milimoles/L) & $2 \times 10^{-6}$ & $2.4 \times 10^{-5}$ \\
4 & $\mathrm{RuCl}_{3}($ milimoles/L) & $2 \times 10^{-9}$ & $2.93 \times 10^{-7}$ \\
5 & $\mathrm{NaNO}_{3}($ moles/L) & $1 \times 10^{-2}$ & 2 \\
6 & $\mathrm{Na}_{2} \mathrm{CO}_{3}$ (moles/L) & & $5 \times 10^{-2}$ \\
7 & $\mathrm{CaCl}_{2}$ (moles/L) & $2 \times 10^{-3}$ & $5 \times 10^{-3}$ \\
8 & $\mathrm{NaOH}_{\text {(moles/L) }}$ & Traces for adjustment of $\mathrm{pH}$ & \\
\hline
\end{tabular}

Table 2: Different Glass Compositions prepared (wt \%)

\begin{tabular}{lcccccccc}
\hline Glass & $\mathrm{SiO}_{2}$ & $\mathrm{PbO}$ & $\mathrm{BaO}$ & $\mathrm{Fe}_{2} \mathrm{O}_{3}$ & $\mathrm{CeO}_{2}$ & $\mathrm{SrO}_{2}$ & $\mathbf{P}_{2} \mathbf{O}_{5}$ & Uranyl acetate \\
\hline LIP3 & - & $49\left(\mathrm{~Pb}_{3} \mathrm{O}_{4}\right)$ & - & 8 & 10 & - & 33 & - \\
LIP4 & - & 52.4 & - & 7.9 & 6.5 & - & 33.2 & - \\
LIP5 & - & $49\left(\mathrm{~Pb}_{3} \mathrm{O}_{4}\right.$ & - & 8 & - & 10 & 33 & - \\
LIP6 & - & $49\left(\mathrm{~Pb}_{3} \mathrm{O}_{4}\right.$ & - & 8 & 5 & 5 & 33 & - \\
LIP7 & - & $49\left(\mathrm{~Pb}_{3} \mathrm{O}_{4}\right.$ & 10 & 8 & - & - & 33 & - \\
LIP8 & - & 52.4 & - & 7.9 & - & - & 33.2 & 6.5 \\
LIP9 & - & 51.4 & - & 7.9 & 10 & - & 33.2 & 7.5 \\
LIP10 & - & 45.8 & & 7.0 & & & 30.2 & 7.0 \\
\hline
\end{tabular}


Table 3: Melting Temperature $\left({ }^{\circ} \mathrm{C}\right)$ and Time of Melting of different glass compositions

\begin{tabular}{lcc}
\hline Glass & M. P. $\left(\mathbf{\pm \mathbf { 2 } ^ { \circ } \mathbf { C } )}\right.$ & Time( mins) \\
\hline LIP3 & 950 & 30 \\
LIP4 & 750 & 30 \\
LIP5 & 900 & 30 \\
LIP6 & 900 & 30 \\
LIP7 & 950 & 30 \\
LIP8 & 900 & 60 \\
LIP9 & 900 & 60 \\
LIP10 & 950 & 60 \\
\hline
\end{tabular}

figure 2. Figure shows the plot of variation of $\mathrm{pH}$ against time (in hour) for different glass systems. The curve for LIP 7 runs lowest. The slightly increasing trend in the $\mathrm{pH}$ values may be due to the mixed oxide of phosphate system. The observed $\mathrm{pH}$ values are in good agreement with the equilibrium $\mathrm{pH}$ values of glass system having composition close to present work ${ }^{5}$. The result can be explained considering the following equilibrium in the aqueous system:

$$
\mathrm{H}_{2} \mathrm{O} \Leftrightarrow \mathrm{H}^{+}+\mathrm{OH}^{-}
$$

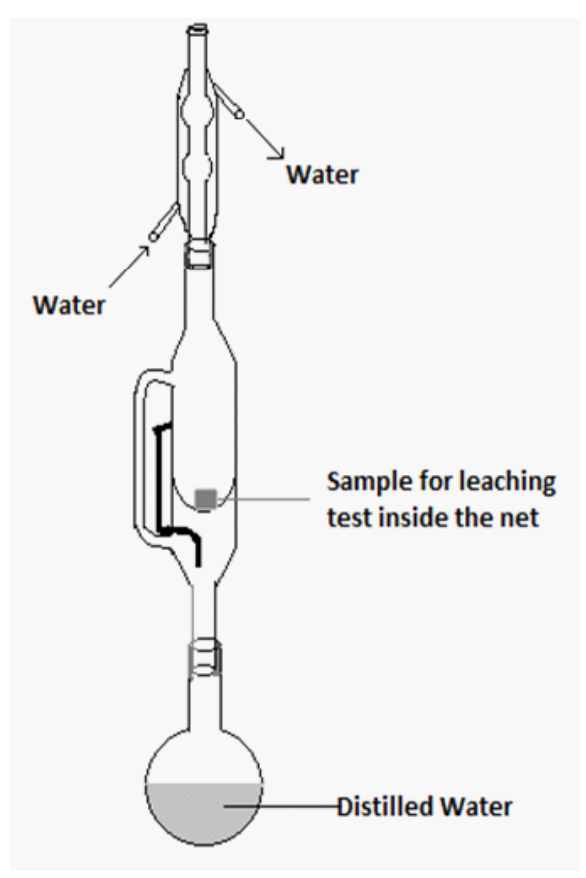

Fig. 1: Schematic of Soxhlet apparatus
The extent of which (i.e., the forward or the reverse direction) is influenced by the different modifier ions released during the leaching of the glass sample. The ionic radii $(\AA)$ of the different modifier ions in our case are $\mathrm{Pb}^{2+}(1.33), \mathrm{Ba}^{2+}(1.35), \mathrm{Fe}^{3+}$ (0.69), $\mathrm{Ce}^{4+}(1.18)$ and $\mathrm{Sr}^{4+}(1.13)$. The corresponding ionic potential increases as $\mathrm{Ba}^{2+}(1.48)<\mathrm{Pb}^{2+}(1.5)<$ $\mathrm{Sr}^{4+}(1.54)<\mathrm{Ce}^{4+}<$ (3.39) $\mathrm{Fe}^{3+}$ (4.69). Now greater the ionic potential of $\mathrm{M}^{\mathrm{n}+}$, more it will attract $\mathrm{OH}^{-}$ions to form the corresponding hydroxides $\mathrm{M}(\mathrm{OH})_{n}$. This formation of hydroxide shifts the dissociation of $\mathrm{H}_{2} \mathrm{O}$ in the forward direction releasing more number of ion in the medium. Thus the resulting solution will increasingly become acidic with lowering value of $\mathrm{pH}$. The LIP 8 glass contains uranyl acetate $(7.0 \mathrm{wt} \%)$. Since $U$ can act as a good glass former, the resulting glass does not dissociate and the $\mathrm{pH}$ value flattens out at a value just below 6.75 .

Leaching operation was done under Soxhlet distillation condition. For glasses not containing uranium, the results of \% wt. losses at each stage (time in hr.) were taken. For U-containing glasses the wt. loss data was further accompanied from the results of 'radiotracer technique' (cps vs. cumulative time). Figure 3 shows the corresponding plots. It is observed that with increasing cumulative time, the net cps (alpha or beta) is decreasing in an exponential way signifying that with increasing leaching time, the release of uranium along with other constituents becomes slower and slower until getting stopped. Thus the glass becomes resistant to leaching and is a better choice for the disposal of nuclear waste compared. In case of LIP9 glass, a similar type of plot is obtained. The exponential decay must not be confused with the decay of $\mathrm{U}^{238}$, the present isotope present in the system, since its half life period is too high $\left(\sim 10^{8}\right.$ years) to be reflected in such decay.

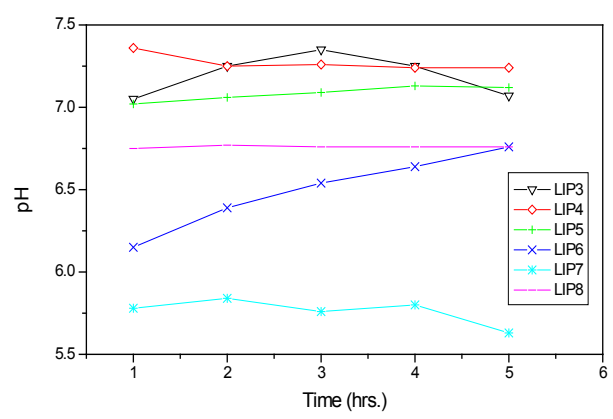

Fig. 2: Plot of pH vs Time for LIP glasses 


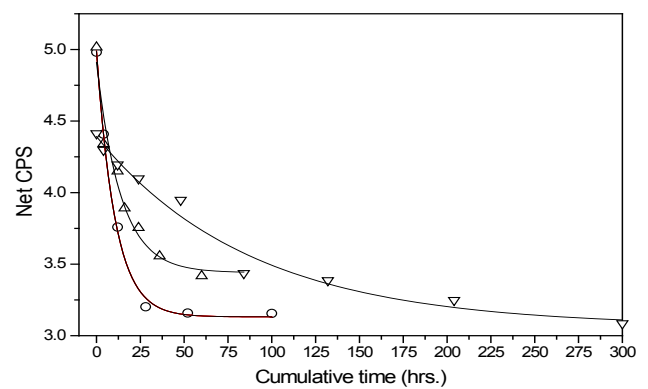

Fig. 3: Net CPS vs. Cumulative time for (o) LIP8, $(\Delta)$ LIP 9 and $(\nabla)$ LIP10

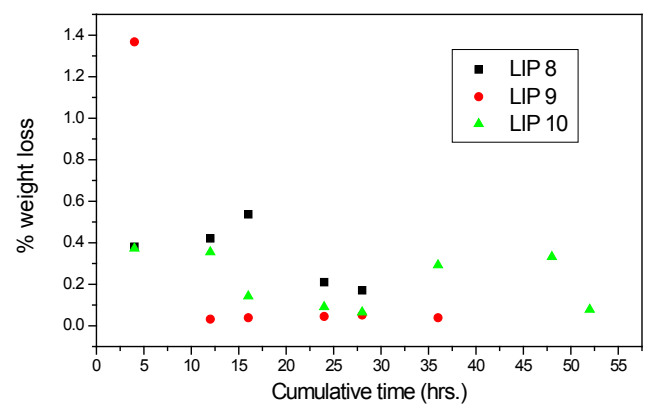

Fig. 4: Percent wt. loss vs. Cumulative time

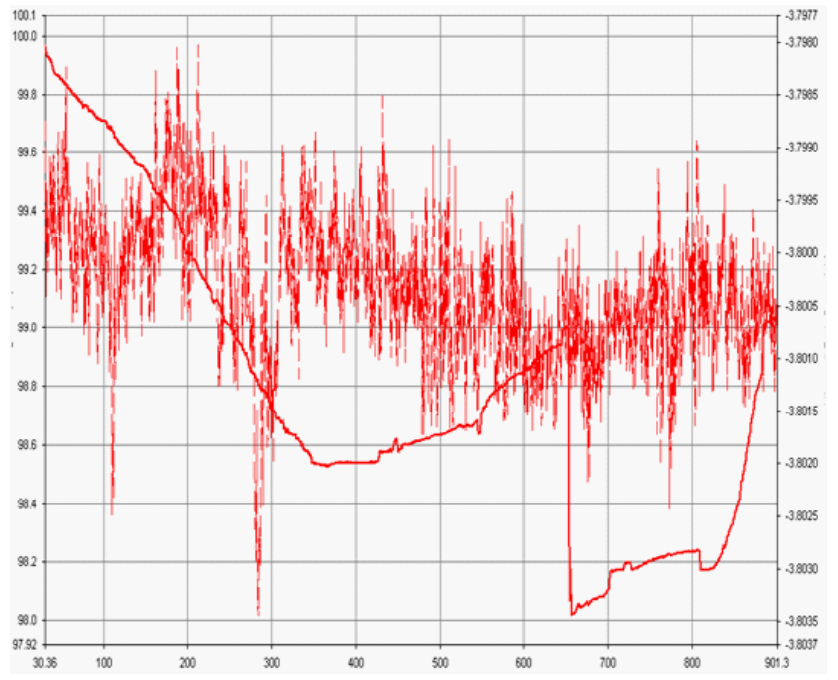

Fig. 5: DTA Thermogram of LIP 9

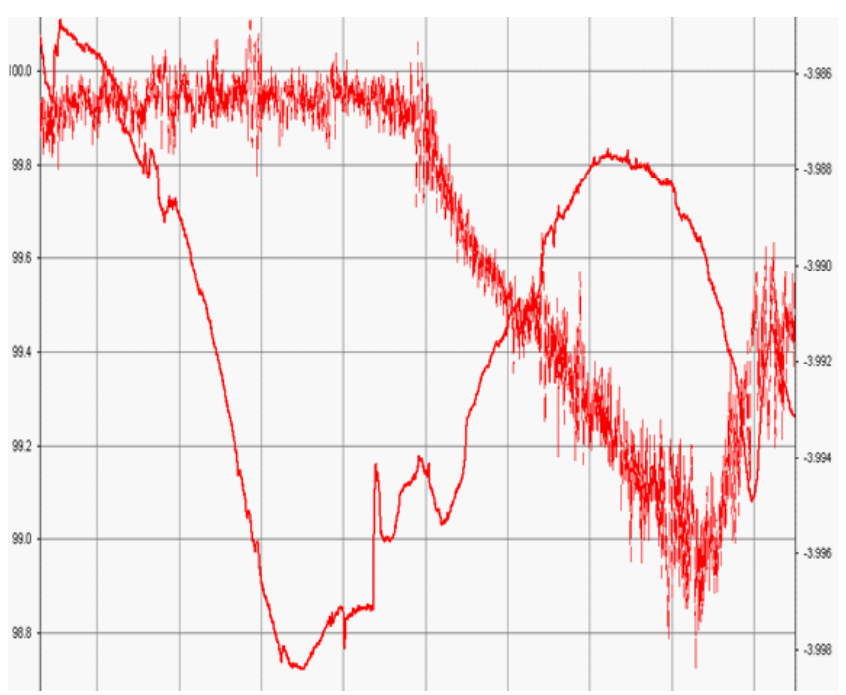

Fig. 6: DTA Thermogram of LIP10 
The leach rates (LR) for LIP8 and LIP9 after leaching are determined from BET surface area analysis. These are $1.8 \times 10^{-3} \mathrm{~g} \cdot \mathrm{m}^{-2} . \mathrm{hr}^{-1}$ and 8.2 $x 10^{-4} \mathrm{~g} \cdot \mathrm{m}^{-2} \cdot \mathrm{hr}^{-1}$ respectively. The leach rate (LR) were measured by weight loss according to the relationship

$$
L R=\left(m_{i}-m_{f}\right)(S A \times t) \rightarrow(2)
$$

where $m_{i}$ and $m_{f}$ are the initial and final sample weights respectively, SA is the BET surface area of the sample and $t$ is the time exposed to the leachant.
These rates as compared to other borosilicate a system is 1000 times lower ${ }^{14-16}$ and thus LIP glasses have much improved chemical durability. This is due to $\mathrm{Fe}_{2} \mathrm{O}_{3}$ content and structural role of $\mathrm{Fe}^{2+/ 3+}$, which strengthens the cross bonding between the polyophosphate chains. Percent weight loss studies show a distinct decrease in the \% wt. loss value with extended period of time of leaching signifying that the extent of leaching die down with time (Figure 4). It is observed that the $\%$ wt. loss decreases in the order:

$$
(\text { LIP 10) }>(\text { LIP 8) }>(\text { LIP 9) }
$$

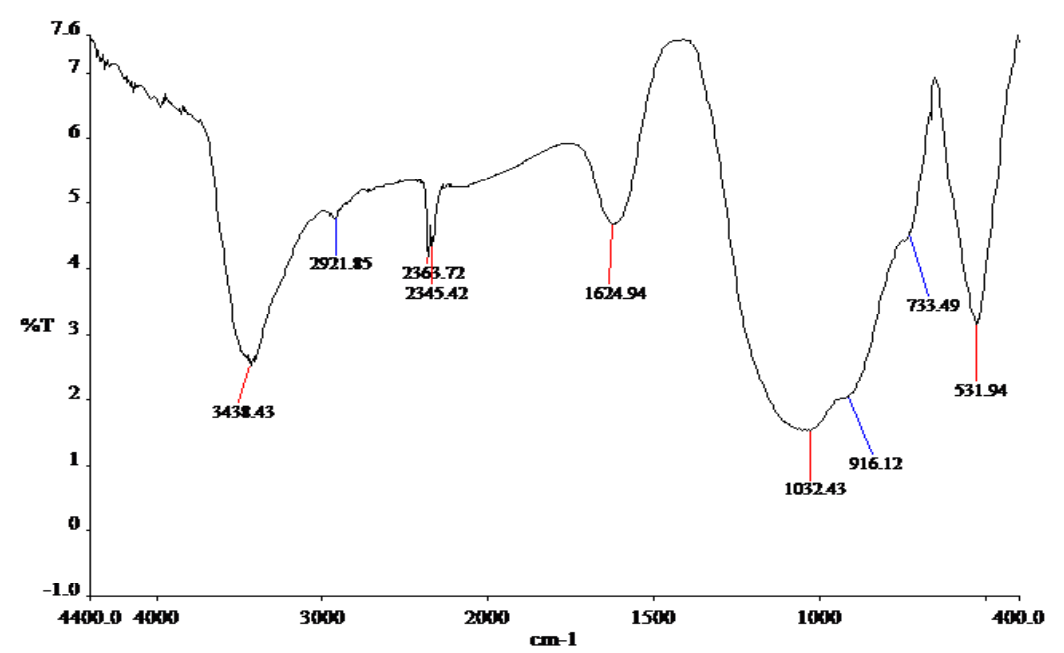

Fig. 7: FTIR Spectrum of LIP 9

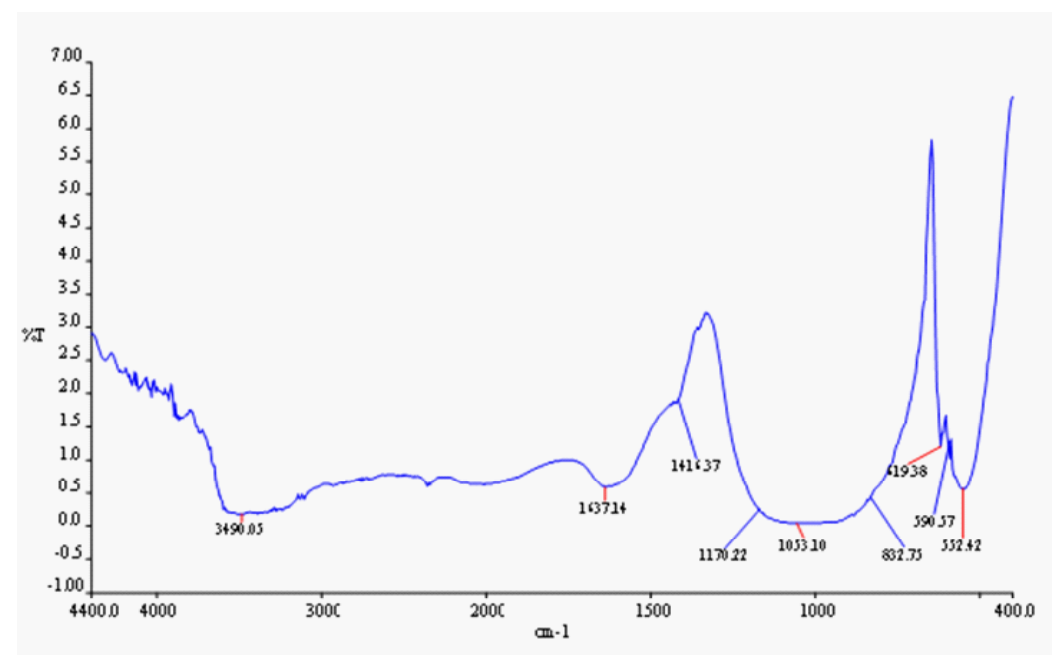

Fig. 8: FTIR Spectrum of LIP 10 


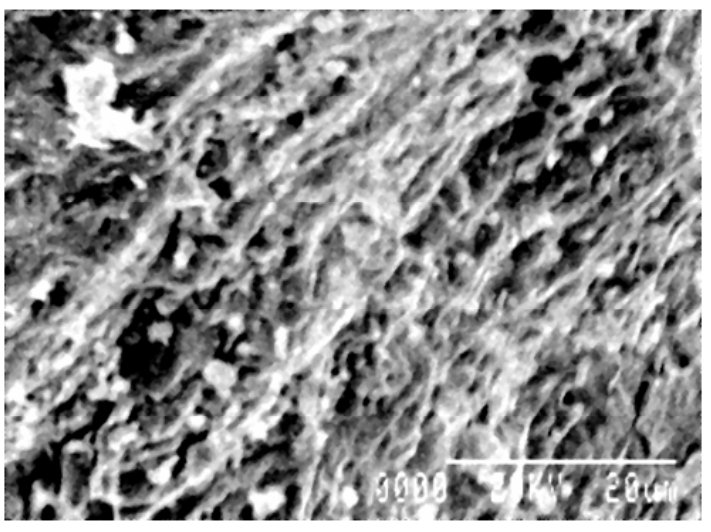

(a)

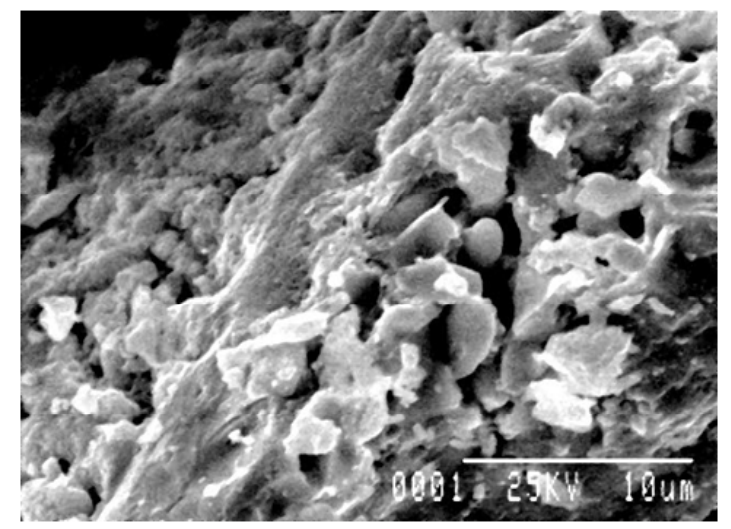

(b)

Fig. 9: SEM Photomicrograph of (a) LIP7 and (b) LIP10 glass

In case of the glass LIP9, $\mathrm{CeO}_{2}$ is present which is not present in LIP8 and LIP10 other. Thus the role of $\mathrm{Ce}$ as binder modifier is evident.

Fig. 5 shows the DTA study of U-containing LIP9 glass and Figure 6 shows the same for LIP10 glass. The thermograms of the above glass samples were taken in the range $30-900^{\circ} \mathrm{C}$. The endotherm at $\sim 400^{\circ} \mathrm{C}$ is due to the peak crystallization temperature. This corresponds to the transition temperature of the base glass. The peak at $\sim 900^{\circ} \mathrm{C}$ corresponds to the liquidus temperature $(\mathrm{TL})$ which corresponds to the melting of the crystalline phase.

Fig. 7 and Figure 8 shows the FTIR spectrum of LIP 9 and LIP 10 glasses respectively. Major stretches are observed at 532, 1025, 1620$1640, \sim 2365$ and $\sim 3440-3490 \mathrm{~cm}^{-1}$ respectively. The IR stretch at $\sim 532 \mathrm{~cm}^{-1}$ may be related to the to phosphate motion ( $\mathrm{P}-\mathrm{O}$ bending vibration $)^{15}$, the one at $\sim 1025 \mathrm{~cm}^{-1}$ is related to the symmetry stretch of non-bridging oxygen ${ }^{16}$. The stretch at $\sim 2365 \mathrm{~cm}^{-1}$ stretch is related to $\mathrm{P}-\mathrm{OH}$ stretching ${ }^{17}$ and the one in the range $3440-3490 \mathrm{~cm}^{-1}$ is related to the $\mathrm{OH}$ stretching (phosphate glass absorbs moisture from atmosphere). Figure 9 shows the SEM images of some selected glass systems. The pictures reveals homogeneous nature of that the glasses formed.

\section{CONCLUSION}

The combination of lead phosphate glasses with various types of simulated nuclear waste showed that it is possible to have a waste-form with corrosion rate 1000 times less than that of a comparable borosilicate glass. The addition of iron to lead phosphate glass was found to increase the chemical durability of the glass and to suppress the tendency for crystallization on cooling and reheating. The durability test shows that the alkaline earth oxides $\mathrm{BaO}$ and $\mathrm{SrO}$ decrease the durability while $\mathrm{PbO}$ improves the corrosion resistance.

LIP glasses have several distinct advantages: (i) Solidified forms have dissolution rates in water about several orders lower than comparable borosilicate formulations. The addition of iron to lead phosphate glass was found to dramatically increase chemical durability of the glass ( by a factor of about $10^{4}$ for $9 \mathrm{wt} \%$ iron oxide addition), (ii) a processing temperature that is $100^{\circ}$ to $250^{\circ} \mathrm{C}$ lower. Effect of modifier ions on melting temperature is evident in the present work and (iii) a much lower melt viscosity in the temperature range from $750^{\circ}$ to $950^{\circ} \mathrm{C}$. Most significantly, the lead-iron phosphate waste form can be processed using a technology similar to that developed for borosilicate nuclear waste glasses.

\section{ACKNOWLEDGEMENTS}

Discussions with Dr. J. Mukerji and Dr. A. S. Sanyal, retired Scientists, CGCRI, Kolkata, is duly acknowledged. The help rendered by Dr. N. Dutta, Bankura Unnayani Institute of Engg., W.B., in setting the Soxhlet system is acknowledged. Financial assistance by DSA (Chemistry) and CAS (Physics) and state funded fellowship provided to one Research Fellow (A. G.) is also acknowledged. 


\section{REFERENCES}

1. Mukerji J., Sanyal A. S., Glass Technol., 45, 117 (2004).

2. Day D. E., Atm. Environ., 35: 5169 (2001).

3. Sales B. C., Boatner L. A., Science, 226: 45 (1984).

4. S.H. Fathabad and H. Hasanvandi, Orient J. Chem., 28(3): 1311-1319 (2012).

5. S.F. Alshmmary and R.V. Nadh, Orient J. Chem., 28(4): 1515-1522 (2013).

6. Day D. E., Chandra S. R., Kim C.W., Annual Report for DOE FG07-96ER45618. University of Missouri-Rolla, Rolla, MO (USA): 2002 June.

7. Malik P. P., Hajra G., Mitra P., Das T., Prog. in Th. and Appl. Phys., 1: 1 (2013).

8. Sanyal A. S., Mukerji J., J. Scientific \& Industrial Res., 33, 436 (1974).

9. Yanagi T., Yoshizoe M., Nakatsuka N., J. Nuclear Sc. and Technol., 25: 661 (1988).

10. Reis S. T., Martinelli J. R., J. Non-Cryst. Solids., 274: 241 (1999).
11. Islam M. M., Holand D., Scales C. R., Phys. Chem. Glasses - European J. Glass Sc. and Technol B., 49: 229 (2008).

12. Hazra G., Das T., Mitra P., "Role of lead as modifier on the properties of lead iron phosphate glasses", Proc. of Nuclear and Radiation Chem.; Feb 22-26; Vishakhapatnam (India). p. 449-450 (2011).

13. Jana S., Karmakar B., Kundu P., Mat. Sc. Pol., 25: 1127 (2007).

14. Fang X., Ray C. S., Milankovic A. M., Day D. E., J. Non-Cryst. Solids, 283: 162 (2001).

15. Yanagi T., Yoshizoe T., Kuramoto K., J. Nucl. Sc. and Technol., 26: 948 (1989).

16. Shih P. Y., Mat. Chem. Phys., 84: 151 (2004).

17. Hudgens J., Brow R. K., Tallatant D. R., Martin S. W., J. Non-Cryst. Solids, 223: 21 (1998).

18. Doweidar H., MoustafaY. M., El-Egili K., Abbas I., Vibrational Spectros., 37: 91 (2007).

19. Brow R. K., Tallant D. R., Myers S. T., Phifer C. C., J. Non-Cryst. Solids, 191: 45 (1995). 